\title{
TERRITORIALIDADE QUILOMBOLA, DIREITOS SOCIAIS E CRIMINALIZAÇÃO ÉTNICA EM UNIDADES DE CONSERVAÇÃO'
}

\section{Wagner Giron²}

\section{iD ORCID IDS}

Giron W - https://orcid.org/0000-0003-4366-714X

\section{Resumo}

A intervenção do Estado no campo ambiental, por meio da criação das Unidades de Conservação sobrepostas aos territórios ancestrais de Comunidades Remanescentes de Quilombos produz uma série de conflitos, não só pela transposição dos territórios comunais, de maneira vertical, ao domínio do Estado mas, principalmente, pelas restrições e forte marginalização que os equipamentos conservacionistas oficiais impõem às comunidades quilombolas, gerando sua asfixia social e dissolução etnocultural. O presente trabalho se estruturou pelas seguintes hipóteses: (i) não há colisão entre os princípios da tutela ambiental e o direito territorial titularizado pelas comunidades tradicionais; (ii) as Unidades de Conservação de Proteção Integral, no Estado de São Paulo, tal como instituídas, não escapam incólumes a um controle de convencionalidade perante a juridificação dos direitos humanos. Este trabalho objetiva analisar o conflito entre os dois valores enunciados, bem como a validade das Unidades de Conservação, no que tangem ao território das comunidades quilombolas, face a carta internacional dos direitos humanos. Para tanto, como metodologia optou-se pela revisão de literatura sobre o tema.

Palavras-chave: Direitos Humanos. Comunidades Quilombolas. Unidades de Conservação. Territorialidade.

\begin{abstract}
The State's intervention in the environmental field, through the creation of Conservation Units overlaid on the ancestral territories of Quilombos Remaining Communities, produces a series of conflicts, not only for the transposition of communal territories, in a vertical way, to the State domain, but mainly, due to the restrictions and strong marginalization that official conservation equipment imposes on quilombola communities, generating their social asphyxiation and ethnocultural dissolution. The present work was structured according to the following hypotheses: (i) there is no collision between the principles of environmental protection and the territorial law held by traditional communities; (ii) Integral Protection Conservation Units, in the State of São Paulo, as established, do not escape unscathed from a conventionality control before the juridification of human rights. This work aims to analyze the conflict between the two stated values, as well as the validity of the Conservation Units, in what concerns the territory of quilombola communities, in view of the international charter of human rights. Therefore, as a methodology, we opted for a literature review on the topic.
\end{abstract}

Keywords: Human Rights. Quilombola Communities. Conservation units. Territoriality.

1 Este artigo é um resumo do trabalho de conclusão de curso apresentado na Escola de Direito da Fundação Getúlio Vargas/SP, em 2017, intitulado "Territorialidade quilombola, direitos humanos e unidades de conservação no Estado de São Paulo", como requisito parcial para a obtenção do título de Pós-Graduação em Direitos Humanos e Acesso à Justiça.

2 Defensoria Publica SP

Correspondência: sabrinadinizbn@gmail.com

Recebido em 01 de Junho de 2020; Aceito em 01 de Dezembro de 2020. 
"Sinuosa até na violência, negadora de virtudes sociais, contemporizadora e narcotizante de qualquer energia realmente produtiva, a 'moral das senzalas' veio a imperar na administração, na economia e nas crenças religiosas dos homens do tempo. A própria criação do mundo teria sido entendida por eles como uma espécie de abandono, um languescimento de Deus"

Sérgio Buarque de Holanda

\section{1 - INTRODUÇÃO}

As Comunidades Quilombolas, ou Comunidades Remanescentes de Quilombos, sofrem historicamente com a ação e omissão estatal no que diz respeito aos seus direitos humanos. Ação no que concerne à sua criminalização e omissão quando não efetiva direitos garantidos nas legislações nacionais e supranacionais.

A intervenção do Estado no campo ambiental, por meio da criação das Unidades de Conservação sobrepostas aos territórios ancestrais de Comunidades Remanescentes de Quilombos produz uma série de conflitos, não só pela transposição dos territórios comunais, de maneira vertical, ao domínio do Estado mas, principalmente, pelas restrições e forte marginalização que os equipamentos conservacionistas oficiais impõem às comunidades quilombolas, gerando sua asfixia social e dissolução etnocultural.

O presente trabalho se estruturou pelas seguintes hipóteses: (i) não há colisão entre os princípios da tutela ambiental e o direito territorial titularizado pelas comunidades tradicionais; (ii) as Unidades de Conservação de Proteção Integral, no Estado de São Paulo, tal como instituídas, não escapam incólumes a um controle de convencionalidade perante a juridificação dos direitos humanos.

Este trabalho objetiva analisar o conflito entre os dois valores enunciados, bem como a validade das Unidades de Conservação, no que tangem ao território das comunidades quilombolas, face a carta internacional dos direitos humanos. Para tanto, como metodologia, optou-se pela revisão de literatura sobre o tema.

Para melhor compreensão das minúcias que trazem o assunto, é fundamental que se esclareça conceitos, legislações e sua aplicação empírica. Sendo assim, serão abordados os conceitos de Quilombo e comunidade Quilombola, assim como o de Comunidade Tradicional, partindo da realidade histórica até os dias atuais.

Em um segundo momento, serão analisadas as questões ambientais sob o aspecto das comunidades tradicionais. Em seguida, alguns instrumentos normativos nacionais e internacionais, que tratam dos direitos dessas comunidades, a serem efetivados e garantidos pelo Estado.

Por fim, é analisado o suposto conflito entre direito ambiental e direitos das comunidades Quilombolas, a partir da sobreposição das Unidades de Conservação a essas comunidades no estado de São Paulo.

\section{2 - QUILOMBOS E SEUS SIGNIFICADOS}

Quilombo é palavra de significado forte, enraizada na história. Indicativa de espaço de severas disputas, situado na fronteira étnico-cultural (VIEIRA, 2014, p. 63) e confinado nas tensões entre a primazia de forças cingidas à sociedade hegemônica e os modos de reprodução comunitários com fortes traços pré-modernos.

Até hoje, pelas forças do atraso ${ }^{1}$ seu significado é discutido dentro não só do sistema de justiça mas principalmente nos centros de produção de decisões políticas, cuja ideologia tende a manter as simbologias ligadas a esses espaços comunais na mais absoluta invisibilidade, negando, esvaziando, esvanecendo no abandono da história oficial, a força dos direitos fundamentais que sustentam as bases territoriais desses segmentos étnicos, imbricados, de maneira iniludível, à própria conformação do Brasil enquanto nação.

$\overline{1}$ Ver Ação direta de inconstitucionalidade no 3239, que visa invalidar os termos do Decreto-federal no 4.887, de 20 de novembro de 2003, que regulamenta o procedimento administrativo de titulação das terras quilombolas. Brasil, Supremo Tribunal Federal. ADIn 3239. 
Gilberto Freire, sobre essa inegável influência da cultura africana na personificação nacional: "Todo brasileiro, mesmo o alvo, de cabelo louro, traz na alma, quando não na alma e no corpo [...] so sombra, ou pelo menos a pinta, do indígena e do negro. A influência direta, ou vaga e remota, do africano. Na ternura, na mímica excessiva, no catolicismo em que se deliciam nossos sentidos, na música, no andar, na fala, no canto de ninar menino pequeno, em tudo que é expressão sincera de vida, trazemos quase todos a marca da influência negra." (FREIRE, 1998, p. 283)

Calha também demarcar a forte carga de preconceito que, corridos cinco séculos da introdução do elemento africano como escravo nestas longitudes, interdita a realização da justiça histórica que deveria se materializar através do reconhecimento e titulação dos territórios ocupados por seus remanescentes.

Quilombo é também espaço de disputas por liberdade, emancipação e perspectivas de dignidade de vida forjado pelas minorias oprimidas frente ao avanço de um modo de produção e acumulação de capital que só tende a superar e destruir as formas tradicionais de vivência societária.

Claus Offe, citado por Arrechtche, enfatiza: “[...] Em seu desenvolvimento, o capitalismo destrói formas anteriores de vida social (ou instituições sociais) gerando disfuncionalidades, que se expressam sob a forma de problemas sociais", p 16. Fenômeno que se aplica exemplarmente ao processo de proletarização passiva vivido pelas comunidades Quilombolas ao longo do tempo. Proletarização passiva: que se refere ao processo pelo qual um indivíduo é destituído dos meios próprios de subsistência, sendo obrigado a vender sua força de trabalho em centros industriais ou urbanos. (ARRETCHE, 1995, p 18).

Fruto social, e político, do processo de espoliação colonial, cujos saques de recursos naturais e mão de obra escravizada tornaram possível o desenvolvimento econômico das formas modernas de produção industrial nos centros capitalistas, no mesmo passo que consolidaram a dependência e subdesenvolvimento na América Latina², os remanescentes das comunidades quilombolas, abandonados pela história oficial, ainda vivenciam o pesado legado do passado patriarcal, calcado em acentuado racismo por parte dos gestores da sociedade hegemônica ${ }^{3}$, que não só desdenham com seus direitos territoriais como atuam, de forma assombrosamente aberta, à mercê de ações e omissões, pelo esvaziamento do conteúdo de tais direitos. Em que pese a vasta juridificação de direitos humanos, no âmbito interno e externo, a amparar o direito basilar de reprodução etnocultural dessas minorias, paira sempre o peso da maldição patriarcal, há muito detectada nas raízes do país por Sérgio Buarque de Holanda, cuja ideologia engendra "constituições feitas para não serem cumpridas, as leis existentes para serem violadas, tudo em proveito de indivíduos e oligarquias" (HOLANDA, 1998, p. 182).

Essas reminiscências do passado escravista não podem ser descartadas em quaisquer análises que se prendam à tão protraída pretensão à bases territoriais seguras, vindicadas pelas incontáveis comunidades quilombolas espalhadas pelo país, e ganham significado revigorado quando divisamos o número diminuto, quase que insignificante, de quilombos devidamente titulados neste estado e país desde o advento da Constituição de 1988.

O movimento Quilombola indica aproximadas 3000 aquilombamentos reivindicando titulação no país, ao passo que, até 2008, apenas 143 núcleos comunais conseguiram a titulação (JESUS et al, 2008).

No Estado de São Paulo, segundo a Comissão Pró-Índio (CPI, 2017) esse número é ainda mais insignificante: apenas 5 comunidades, de um total de 35, conseguiram acessar titulação nestes últimos 30 anos.

Para o ITESP - Fundação Instituto de Terras do Estado de São Paulo-, órgão encarregado do procedimento de titulação das terras quilombolas, o número de regularizações também é inexpressivo no Estado: apenas seis comunidades tituladas (ITESP, 2017).

São vários os fatores a emperrar, por tempo imemorial, o ato, estatal, de regularização fundiária das 
Comunidades Remanescentes de Quilombos. Podem ser assim resumidos: (i) falta de vontade política dos exercentes da esfera de poder; (ii) força centrípeta dos setores ligados à especulação imobiliária e agronegócio que visam aprofundar seus domínios sobre os territórios comunais; (iii) edificação de unidades de conservação ambiental, em especial de proteção integral, a restringir os modos de reprodução material e cultural dessas comunidades, tudo isso forjando um avançado processo de marginalização e criminalização dos integrantes dos quilombos que só tende à esvanecer as chances de sobrevivência dessas etnias.

Esse legado racial se agravou, por variadas formas, nos dias de hoje. A Anistia Internacional, analisando dados de 2004 a 2007, estima "em mais de 192 mil os homicídios no país. No mesmo período, os doze maiores conflitos mundiais totalizaram 170 mil mortes. Mesmo diante desse cenário dramático, a taxa de resolução dos homicídios no país é de apenas 8\%" (DIAS, 2015). Grande parte dessa violência é direcionada contra a população negra. Segundo a pesquisa Mapa da Violência em 2014 o país registrou 44,861 mil homicídios por arma de fogo, dos quais 27,4 mil foram de vítimas negras. A mesma pesquisa aponta que, em 2003, o potencial de vitimização da população negra no Brasil girava em torno de 71,7\% dos homicídios. Em 2014 essa potencialidade de letalidade racial saltou para 158,9\% (MAPA, 2016. p.16 e 59)

As circunstâncias impostas pelos ciclos de acúmulo de capital que urdiram todo o processo colonial-escravocrata, o preconceito estrutural até hoje reinante, a ausência de políticas públicas decentes e consistentes, que possibilitassem ao menos amenizar as severas sequelas de injustiças desse débito social imenso, compeliram frações dessas minorias étnicas a buscarem refúgio nos distantes espaços florestais, na periferia da ordem social competitiva (FERNANDES, 2007, p.87) onde, através dos séculos, e juntamente com outros elementos não negros que também vindicavam um vislumbre de liberdade diante das restrições impostas pela sociedade hegemônica (ROTHENBURG, 2008, p. 190), se enraizaram em territórios tradicionais, visceralmente ligados à própria essência material e imaterial desses agrupamentos, que tornaram esses espaços compartilhados pela tradição - e não por obra do acaso- nos fragmentos mais bem conservados do que restou dos maciços florestais dos biomas originários neste Estado.

Hodiernamente, o conceito normativo de Comunidade Quilombola, vem descrito no artigo 20 do Decreto no 4.887, de 20 de novembro de 2003 :

Consideram-se remanescentes das comunidades dos quilombos, para fins deste Decreto, os grupos étnico-raciais, segundo critérios de autoatribuição, com trajetória histórica própria, dotados de relações territoriais específicas, com presunção de ancestralidade negra relacionada com a resistência à opressão histórica sofrida.

Talvez em um dos raros hiatos temporais da história deste país em que os movimentos populares puderam experimentar um laivo de protagonismo, que se deu por ocasião da última vertente do Poder Constituinte em meio à década de oitenta do século passado, pelos esforços e organização dos segmentos jungidos aos grupos de luta pela Consciência Negra (PRIOSTE E BARRETO, 2012) é que, nos estertores do processo de conformação constitucional, se fez inserir, no artigo 68 dos Atos das Disposições Constitucionais Transitórias, o seguinte preceptivo: "aos remanescentes das comunidades dos quilombos que estejam ocupando suas terras é reconhecida a propriedade definitiva, devendo o Estado emitir-Ihes os títulos respectivos".

Esse direito fundamental à territorialidade comunal, que deveria ser implementado rapidamente, posto que "transitório", passados trinta anos da promulgação da Constituição ainda está muito longe de ser respeitado em sua inteireza, como visto linhas trás.

Além desse preceptivo, no corpo da Constituição, pela primeira vez na história do país (PRIOSTE E BARRETO, 2012) se reconheceu a ancestralidade da etnia negra e sua descendência, sua cultura e aquilombamentos como elementos formadores da cultura nacional e do processo civilizatório do Brasil, erigindo-os, junto a outras etnias e grupos populares tradicionais, como elementos integrantes do patrimônio cultural brasileiro. ${ }^{4}$

4 Esses preceitos estão nos artigos 215, §1으 e 216 e §5으 da Constituição Federal.

Revista Ciências Humanas - UNITAU, Taubaté/SP - Brasil, v. 13, n 3, edição 28, p. 130 - 144, Setembro/Dezembro 2020 
Os documentos afetos aos territórios quilombolas, ademais, foram tombados diretamente pelo texto constitucional (artigo 216, §5ㅇ, da CF) face à sua relevância para a conformação cultural brasileira.

\section{3 - COMUNIDADES TRADICIONAIS, TUTELA SOCIOAMBIENTAL E CONFLITOS TERRITO- RIAIS}

Inexistindo políticas públicas no período pós-escravista capazes de minorar os perversos efeitos do regime de servidão e pudessem, ao menos, preparar o seu agente humano para o labor livre, o escravo foi convertido em um resíduo social racial (FERNANDES, 2007, p. 87), relegado ao estamento mais baixo da população pauperizada, e expulso para as fronteiras periféricas da ordem social (PRADO JR., 2008). Nesses espaços, via de regra embrenhados em maciços florestais isolados, estabeleceu territórios onde, de forma tradicional, pré-moderna, por séculos reproduziu, com forte suporte em sua cultura ancestral e vasto conhecimento das dinâmicas da natureza, a subsistência material dos aquilombamentos, enquanto espécie das comunidades tradicionais. ${ }^{5}$

Por conta de uma cosmovisão profundamente cingida à natureza e pertencimento identitário intrinsecamente ligado às bases territoriais, o que mantém a reprodução material estritamente dependente do manejo sustentável dos recursos naturais, as comunidades tradicionais são as principais responsáveis pela preservação do que restou dos fragmentos remanescentes dos biomas nacionais originários ${ }^{6}$ por

$5 \quad$ O conceito de comunidades tradicionais é amplo. De forma geral abrange não só os remanescentes de quilombos, mas também as etnias indígenas e inúmeras populações. Segundo o Centro Nacional de Populações Tradicionais - CNPT do Instituto Brasileiro de Meio Ambiente e Recursos Naturais Renováveis - IBAMA, as Comunidades Tradicionais abarcam ainda: ciganos, pomeranos, ribeirinhos, caiçaras, quebradeiras de coco babaçu, seringueiros, pescadores artesanais, agroextrativistas da Amazônia, povos dos faxinais dos fundos de pasto, geraizeiros, pantaneiros, retireiros e comunidades de terreiros. (VIEIRA, 2014, p.34). 6 Diegues, 1996, p.87. Grabner, 2016, p. 69. Hayama, 2013, p. 262. Rothenburg, out/2008. Sarmento, 2006. SILVA, 2008 7 O reconhecimento do baixo impacto socioambiental inerente ao modo de subsistência das comunidades tradicionais está amplamente cristalizado em várias normas. A propósito, ver: Decreto federal no 6.047/2007, que instituiu a Política Nacional de Desenvolvimento Sustentável dos Povose Comunidades Tradicionais. Lei no 11.428/2006 (Lei da Mata Atlântica), artigo 3, II: "população tradicional: população vivendo em estreita relação com o ambiente natural, dependendo de seus recursos naturais para a sua repro- isso, no Estado de São Paulo, os territórios quilombolas estão embrenhados, na grande maioria dos agrupamentos, nas áreas recobertas pela Mata Atlântica, um dos motivos pelos quais quase que inexistem remanescentes de quilombos que não estejam à mercê de qualquer espécie de processo, judicial ou administrativo, tendente a expulsá-los dos territórios (PRIOSTE E BARRETO, 2012).

Os pobres e os negros, libertos ou não, foram proibidos, na era escravista, de serem proprietários de terras sob a égide da ideologia dominante, cristalizada pela "Lei de Terras" de 1850 (PRIOSTE E BARRETO, 2012), a qual, segundo Stédile "consolidou o latifúndio como estrutura básica da distribuição de terras no país" (2011, p. 16). Os territórios comunais ocupados, portanto, o foram à margem do sistema hegemônico de regulamentação do domínio, na fronteira étnico-cultural em que os povos tradicionais não reconhecem as normas produzidas pela sociedade dominante (VIEIRA, 2014, p. 23), divorciados dos significados liberais afetos à relação de posse privada, com ostensivo conteúdo coletivo no manejo do solo ancestral.

Todavia, os conflitos entre essas sociedades tradicionais e a ordem social moderna se intensificaram, principalmente neste Estado, a contar do último período ditatorial quando, por decretos verticais, impostos de cima para baixo, e sem quaisquer chances de diálogo ou informação prévia com as comunidades tradicionais, se reproduziu a racionalidade conservacionista gestada nos países centrais do capitalismo, aqui adensando um ciclo preservacionista radical, fincado no mito moderno da natureza intocada ${ }^{8}$ que produziu a instituição serial de várias Unidades de Conservação de proteção integral, principalmente entre as décadas de sessenta a oitenta do século passado (JORDÃO, 2015, p.213), fundadas em uma ideologia que se baseava na ilusão de serem os fragmentos florestais nativos - há séculos ocupados e preservados pelas sociedades pré-capitalistas -,

dução sociocultural, por meio de atividades de baixo impacto ambiental". 8 "[...]A noção de mito naturalista, da natureza intocada, do mundo selvagem diz respeito a uma representação simbólica pela qual existiriam áreas naturais intocadas e intocáveis pelo homem, apresentando componentes num estado 'puro' até anterior ao aparecimento do homem. Esse mito supõe a incompatibilidade entre ações de quaisquer grupos humanos e a conservação da natureza". (DIEGUES, 1996, p. 53). 
enormes espaços vazios de humanidades, com seus ecossistemas "intocados".

No intento de se preservar esses escassos remanescentes de biomas a salvo do avanço do modo de produção urbano-industrial, foram instaladas, no Estado de São Paulo, 72 Unidades de Conservação de proteção integral (JORDÃO, 2015, p.213), das quais, os principais sistemas são: o (i)Parque estadual do PETAR, instituído pelo Decreto $\mathrm{n}$ - 32.283, de 19 de maio de 1958, albergando as unidades conservacionistas de Jacupiranga, Eldorado, Iporanga, Barra do Turvo e Cananéia; (ii) o Parque Estadual da Serra do Mar - PESM, constituído pelo Decreto no 10.251, de 30 de agosto de 1977, que alcança os municípios do Vale do Ribeira, Mongaguá, Mogi das Cruzes, Bertioga, São Sebastião, Caraguatatuba e Ubatuba, parte do Vale do Paraíba como São Luiz do Paraitinga, Paraibuna e Cunha; (iii) Estação Ecológica da Juréia-Itatins nos Municípios de Peruíbe e Iguape; (iv) Parque Estadual da Ilha do Cardoso, em Cananéia; e (v) Parque Estadual de Ilhabela (JORDÃO, 2015, p.213).

Subsequentemente, a Lei no 9.985/2000 veio a instituir o Sistema Nacional de Unidades de Conservação da Natureza - SNUC, concebido, também como já pontuado, pelo mito da natureza intocada, ignorando, por completo, na estruturação de seu texto, as cosmovisões e saberes etnoculturais das populações originárias que ocupavam, desde tempos imemoriais, os espaços protegidos e recobertos pelos biomas naturais, sobrepostos por tais unidades.

A indiferença aos anseios seculares e modos de vida das comunidades tradicionais, em especial as quilombolas, pode ser detectada de maneira vítrea desde o inciso I, do artigo 2 o da norma referida, que conceitua unidade de conservação como:

Espaço territorial e seus recursos ambientais, incluindo as águas jurisdicionais, com características naturais relevantes, legalmente instituído pelo Poder Público, com objetivos de conservação e limites definidos, sob regime especial de administração, ao qual se aplicam garantias adequadas de proteção. ${ }^{9}$

$9 \quad$ Praticamente, os mesmos elementos descritivos contidos no Decreto Estadual no 25.341/1986, anterior à CF de 1988, que instituiu o regulamento dos parques em São Paulo.
Temos, na descrição da norma, todos os elementos assépticos de uma concepção hegemônica, que traça, abstratamente, ao corte do liberalismo ocidental, os significados vazios de conteúdo humano, sem qualquer alusão, nesses moldes normativos, a agrupamentos humanos cujos saberes ancestrais e intergeracionais, de forma efetiva, e não por influxo da edição de uma regra abstrata, conservaram, a salvo dos desastres derivados do avanço das fronteiras de atividades econômicas da ordem urbano-industrial, os fragmentos naturais ainda repletos de biodiversidade.

Com o advento desses equipamentos conservacionistas modernos, se intensificaram as restrições aos modos tradicionais de sobrevivência étnico-cultural das comunidades quilombolas, constituindo-se essas unidades de conservação de proteção integral as principais causas de expulsão das comunidades tradicionais de seus territórios (GRABNER, 2016, p. 82. HAMAYA, 2013, p. 266) ${ }^{10}$

Atividades voltadas à reprodução desses agrupamentos tradicionais, como o cultivo agrícola em escala familiar, caça e a pesca artesanal, construção de moradias etc, passaram a ser intensivamente criminalizadas pelo Estado.

A corroborar essas asserções, Maria Luiza Grabner relata um pouco sobre as restrições aqui consideradas:

[...]No entanto, afirma Diegues, com base em relatos e depoimentos orais colhidos em toda a extensão do território caiçara, que a instalação de áreas protegidas sobrepostas aos seus territórios tradicionais encontra-se na memória mais recente de muitos moradores que tiveram seu modo de vida desrespeitado não só pela proibição de atividades agrícolas e extrativistas habituais mas também pelo deslocamento forçado de suas moradias, ordenados pelos órgãos ambientais gestores das respectivas unidades de conservação. Tais relatos das caiçaras, segundo o mesmo autor, expressam o terror e sofrimento decorrentes da expulsão acrescido da incerteza quanto ao futuro nas periferias das cidades litorâneas, para onde, mais das vezes, acabam sendo empurradas essas popula-

10 Ao todo, esses sistemas conservacionistas abrangem uma área de aproximadamente 970.000,00 hectares, equivalente a 3,9\% do território total do Estado (JORDÃO, 2015, p. 210). 
ções sem contar com o apoio adequado do Estado para que possam reconstruir seu modo de vida peculiar, com base em sua cultura (GRABNER, 2016, p. 84).

Mostra contundente das violências informadoras da intervenção do Estado nesses territórios, pode ser extraída da narrativa contida no Relatório Técnico-Científico (RTC), que instrui o amarelecido, e já decenal, rito administrativo inerente à regularização fundiária do Quilombo da Fazenda, em Ubatuba-SP, referente a brutal remoção impingida à quilombola Laura Braga, nos idos da década de setenta do século passado:

"A minha casa foi demolida, eu tava grávida de 5 ou 7 meses, e chegou o Ivan, na época, juntamente com seus capangas. Eu digo capanga, porque não existia lei, não existia nada, as coisas eram feitas da maneira deles, eles que faziam a lei. Ele chegou juntamente com seus capangas, uns 30 homens, tudo armado na minha porta, dizendo que eu tinha de sair dali.... Acho que era diretor na época, nem sei o que é que aquilo lá era. $\mathrm{E}$ aí dizendo que eu tinha que sair. Eu aleguei que se eu saísse, pra onde eu iria? Sim, porque, até então eu tinha aquilo como a minha casa, um direito meu. Ele falou que eu iria para onde eu quisesse, pra baixo da ponte, que isso não interessava. Três dias depois, eles voltaram na minha casa. Eu carreguei muda de banana lá da Fazenda (sertão) nas costas, grávida, pra plantar, fazer um roçado, que eu tinha um roçado do outro lado do asfalto. Três dias depois, os homens foram lá e cortaram tudo a facão, a minha planta, e vieram me dizer que se eu voltasse a plantar, eles iriam me levar pra cadeia. Eu até tentei, na época, uma rádio em Ubatuba, o seu Zé Pedro me deu uma força, procuramos a autoridade, procuramos a rádio, mas a lei era deles. Era eles que faziam a lei. Me chamaram ainda de mentirosa na rádio e era isso que acontecia" (ANDRADE, 2007, p. 37)

Essas e outras ações repressivas, protagonizadas pelas agências criminalizantes do Estado por conta da racionalidade conservacionista moderna, paralelamente às pressões empreendidas pelos setores empresariais, alimentam a diáspora recaída sobre essas sociedades comunais. ${ }^{11}$

11 Outros exemplos encontramos em processos criminais como o de no 0000655-74.2009.8.26.0642 (SÃO PAULO, 2017a); 000791219.2010.8.26.0642, (SÃO PAULO, 2017, b), e 0006427-42.2014.8.26.0642

\section{4 - OS INSTRUMENTOS INTERNACIONAIS DE DIREITOS HUMANOS}

Para os escopos deste trabalho, o direito étnico-territorial detido pelas Comunidades Quilombolas integra o vasto bloco de juridificação atreita aos direitos sociais, econômicos, culturais, socioambientais etc, sendo a Convenção-169 da Organização Internacional do Trabalho (OIT) "Sobre os Povos Indígenas e Tribais" (1989), um dos principais amparos normativos dessa messe de direitos. Incorporou-se ao âmbito jurídico interno através da aprovação de seu teor pelo Decreto Legislativo no 143 , de 20 de junho de 2002. Posteriormente, foi promulgada pelo Decreto Federal no 5.051, de 19 de abril de 2004.

Porém, antes de sua vigência, já era possível extrair embasamento, no bloco internacional dos direitos humanos, às pretensões de justiça histórico-territorial formuladas pelos remanescentes de quilombos, a começar pelo Artigo XXII da Declaração Universal dos Direitos Humanos, de 1948, que diz:

Toda pessoa, como membro da sociedade, tem direito à segurança social e à realização, pelo esforço nacional, pela cooperação internacional e de acordo com a organização e recursos de cada Estado, dos direitos econômicos, sociais e culturais indispensáveis à sua dignidade e ao livre desenvolvimento de sua personalidade.

A positivação desse consenso universal de que esse ordenamento de direitos de corte social é indispensável ao desfrute dos demais direitos de natureza civil e política, e até mesmo, na linguagem dos próprios tratados, ao ideal do ser humano livre, liberto do temor da miséria, tal qual cristalizado nos considerandos de vários documentos internacionais, como exemplo, na Convenção Americana de Direitos Humanos e no Pacto Internacional dos Direitos Econômicos, ganhou sustentação ao longo das décadas, a ponto de transpor os limites morais de uma conclusão abstrata mais que óbvia, para erigir-se em razão jurídica incidente em qualquer esforço interpretativo para a efetivação dos direitos humanos na contemporaneidade.

(SÃO PAULO, 2017, c), todos do JECRIM da comarca de Ubatuba-SP, que criminalizam ações tradicionais simples como capinação de gramíneas para promoção de festividades, edificação de moradia e construção de um pequeno banheiro com bambu, respectivamente. 
Portanto, nesse marco, o já mencionado Pacto Internacional dos Direitos Econômicos, Sociais e Culturais (1966), promulgado pelo Decreto Federal no 591, de 06.07.1992, complementa o esforço normativo em se robustecer garantias estreitamente alinhadas ao anseio político da comunidade humana em direcionar aos Estados, em seu artigo 2으, o compromisso, ainda que temperado pelos pendores da progressividade, de assegurar essa gama de direitos, sem qualquer discriminação (art. 2‥1).

Aqui um necessário parêntese para ponderar que aos gestores do Estado, até mesmo a réplica de que os direitos à segurança territorial das comunidades quilombolas não são absolutos, e devem ter sua implementação pautada pela "progressividade", não teria a menor valia. Isso porque, como vimos no primeiro capítulo, neste Estado, em quase três décadas da consolidação desse direito no texto constitucional, não mais que cinco quilombos foram titulados, o que evidencia que nem a relativização dos direitos sociais pela lógica da gradualidade está sendo cumprida nesta unidade federativa.

Até mesmo no Pacto Internacional Sobre Direitos Civis e Políticos (1966), aprovado no Brasil pelo Decreto Legislativo no 226, de 12 de dezembro de 1991, e promulgado pelo Decreto $n=592$, de 06 de julho de 1992, temos, no artigo 27 , importante referencial a dar lastro ao direito territorial analisado:

Art. 27: Nos Estados em que haja minorias étnicas, religiosas ou linguísticas, as pessoas pertencentes a essas minorias não poderão ser privadas do direito de ter, conjuntamente com outros membros de seu grupo, sua própria vida cultural, de professar e praticar sua própria religião e usar sua própria língua.

Na órbita continental, a Convenção Americana Sobre Direitos Humanos (Pacto de San José da Costa Rica de 1969), promulgada no Brasil pelo Decreto no 678 , de 06.11.1992, guarnece tais direitos em seu artigo 26, ao dispor:

Artigo 26: Os Estados-partes comprometem-se a adotar as providências, tanto no âmbito interno, como mediante cooperação internacional, especialmente econômica e técnica, a fim de conseguir progressivamente a plena efetividade dos direitos que decorrem das normas econômicas, sociais e sobre educação, ciência e cultura, constantes da Carta da Organização dos Estados Americanos, reformada pelo Protocolo de Buenos Aires, na medida dos recursos disponíveis, por via legislativa ou por outros meios apropriados.

Não é de todo impertinente desde já averbar que, a partir de uma interpretação ampliativa do direito de propriedade elencado no artigo 21 da Convenção, obviamente com a injunção de seu artigo 26 e outras válvulas interpretativas gravadas nesse documento regional, a Corte Interamericana de Direitos Humanos tem estendido às comunidades tradicionais do continente o desfrute do território ancestral nos moldes tangidos pelo etnodesenvolvimento. ${ }^{12}$

Outra vertente em apoio à efetivação dos direitos territoriais analisados, reside no campo etnocultural. O direito à cultura, enquanto direito fundamental, além de assentado no artigo 27 do Pacto Internacional Sobre Direitos Civis e Políticos, também é assegurado a partir dos considerandos da Declaração Americana dos Direitos e Deveres do Homem (1948). Estipula o texto referido: "Os povos americanos dignificam a pessoa humana e que suas Constituições nacionais reconhecem que as instituições jurídicas e políticas, que regem a vida em sociedade, têm como finalidade principal a proteção dos direitos essenciais do homem e a criação de circunstâncias que lhe permitam progredir espiritual e materialmente e alcançar a felicidade. [...]É dever do homem exercer, manter e estimular a cultura por todos os meios ao seu alcance, porque a cultura é a mais elevada expressão social e histórica do espírito". (destacamos)

Além de ser valorizado no espectro das sociedades e povos tradicionais, tanto pelo princípio 22 da Declaração do Rio de Janeiro Sobre Meio Ambiente e Desenvolvimento (1992) como pelo artigo 8, letra 'j' da Convenção Sobre Diversidade Biológica (1992).

12 São os casos da Comunidade Yakye Axa vs. Paraguai, de 17.06.2005; Pueblo Saramaka vs. Suriname, julgado em 28.11.2007; Moiwana vs. Suriname de 2005; Comunidade Indígena Sawhoyamaxa Vs. Paraguai, de 2006; Comunidade Indígena Xákmok Kásek Vs. Paraguai, de 2010 e Povo Indígena Kichawa de Sarayaku Vs. Ecuador, julgado em 2012. Todos procedentes. (MAGNANI, 2013). Os preceptivos mencionados da Convenção Americana são: "Artigo 21.1 Toda pessoa tem direito ao uso e gozo de seus bens.". Destaque-se que o caput do dispositivo não aduz que "toda pessoa tem direito à propriedade privada", mas a "seus bens", porta ampla de interpretação extensiva que tem auxiliado a Corte Interamericana a dilatar o alcance desse direito, de corte liberal, aos anseios etnoterritoriais das comunidades originárias. 
Esses textos trazem a seguinte redação:

Rio/92. Princípio 22: As populações indígenas e suas comunidades e outras comunidades locais desempenham um papel vital na gestão e desenvolvimento do ambiente devido aos seus conhecimentos e práticas tradicionais. Os Estados deverão reconhecer e apoiar devidamente a sua identidade, cultura e interesses e tornar possível a sua participação efetiva na concretização de um desenvolvimento sustentável.

Convenção Sobre Diversidade Biológica (1992)

Art. 8-conservação in situ:

Letra j) Em conformidade com sua legislação nacional, respeitar, preservar e manter o conhecimento, inovações e práticas das comunidades locais e populações indígenas com estilo de vida tradicionais relevantes à conservação e à utilização sustentável da diversidade biológica e incentivar sua mais ampla aplicação com a aprovação e a participação dos detentores desse conhecimento, inovações e práticas".

Exposto esse panorama normativo mais amplo, é curial voltarmos a atenção a dispositivos basilares da Convenção 169 da OIT, que regem o direito ao etnodesenvolvimento incidente sobre os povos originários e agrupamentos tradicionais. A tanto, basta analisarmos os artigos 13 a 16 dessa convenção:

“Artigo

1. Ao aplicarem as disposições desta parte da Convenção, os governos deverão respeitar a importância especial que para as culturas e valores espirituais dos povos interessados possui a sua relação com as terras ou territórios, ou com ambos, segundo os casos, que eles ocupam ou utilizam de alguma maneira e, particularmente, os aspectos coletivos dessa relação.

2. A utilização do termo "terras" nos Artigos 15 e 16 deverá incluir o conceito de territórios, o que abrange a totalidade do habitat das regiões que os povos interessados ocupam ou utilizam de alguma outra forma.

Artigo

1. Dever-se-á reconhecer aos povos interessados os direitos de propriedade e de posse sobre as terras que tradicionalmente ocupam. Além disso, nos casos apropriados, deverão ser adota- das medidas para salvaguardar o direito dos povos interessados de utilizar terras que não estejam exclusivamente ocupadas por eles, mas às quais, tradicionalmente, tenham tido acesso para suas atividades tradicionais e de subsistência. Nesse particular, deverá ser dada especial atenção à situação dos povos nômades e dos agricultores itinerantes.

2. Os governos deverão adotar as medidas que sejam necessárias para determinar as terras que os povos interessados ocupam tradicionalmente e garantir a proteção efetiva dos seus direitos de propriedade e posse.

3. Deverão ser instituídos procedimentos adequados no âmbito do sistema jurídico nacional para solucionar as reivindicações de terras formuladas pelos povos interessados.

Artigo

1. Os direitos dos povos interessados aos recursos naturais existentes nas suas terras deverão ser especialmente protegidos. Esses direitos abrangem o direito desses povos a participarem da utilização, administração e conservação dos recursos mencionados.

2. Em caso de pertencer ao Estado a propriedade dos minérios ou dos recursos do subsolo, ou de ter direitos sobre outros recursos, existentes nas terras, os governos deverão estabelecer ou manter procedimentos com vistas a consultar os povos interessados, a fim de se determinar se os interesses desses povos seriam prejudicados, e em que medida, antes de se empreender ou autorizar qualquer programa de prospecção ou exploração dos recursos existentes nas suas terras. Os povos interessados deverão participar sempre que for possível dos benefícios que essas atividades produzam, e receber indenização equitativa por qualquer dano que possam sofrer como resultado dessas atividades.

ARTIGO

1 Com reserva do disposto nos parágrafos a seguir do presente Artigo, os povos interessados não deverão ser transladados das terras que ocupam.

2 Quando, excepcionalmente, o translado e o reassentamento desses povos sejam considerados necessários, só poderão ser efetuados com o consentimento dos mesmos, concedido livremente e com pleno conhecimento de causa. Quando não for possível obter o seu consentimento, o translado e o reassentamento só poderão ser realizados após a conclusão de 
procedimentos adequados estabelecidos pela legislação nacional, inclusive enquetes públicas, quando for apropriado, nas quais os povos interessados tenham a possibilidade de estar efetivamente representados.

3 Sempre que for possível, esses povos deverão ter o direito de voltar a suas terras tradicionais assim que deixarem de existir as causas que motivaram seu translado e reassentamento.

Esses preceptivos abarcam as comunidades tradicionais, além dos povos originários, pela elasticidade inerente ao termo 'povos indígenas e tribais', constante do artigo primeiro da aludida Convenção.

Além dos direitos atrelados ao território ancestral, acima transcritos, nessa Convenção há ainda o direito fundamental à autoidentificação comunal (artigo 1으, letra "2"); obrigatoriedade dos Estados-partes em efetivar os direitos econômicos, sociais, culturais e socioambientais desses agrupamentos (artigo 2ㅇ), respeitando sempre as peculiaridades culturais de cada grupo ou etnia (artigo 5); direito à consulta prévia e devidamente informada sobre quaisquer atos administrativos, normativos, ou políticas públicas que possam impactar o território e modo de vida das comunidades (artigos 6 e 15); direito das etnias de escolher suas próprias prioridades em termos de desenvolvimento (artigo 70); aplicação da legislação nacional em sintonia aos valores etnoculturais dos povos originários e comunidades tradicionais (artigos 8 a 11) e direito fundamental de acesso aos procedimentos legais (artigo 12).

Em junho de 2016, por aclamação, os Estados membros da OEA-Organização dos Estados Americanos, aprovaram a Declaração Americana Sobre os Direitos dos Povos Indígenas (BRASIL, FUNAI, 2016), que amplia as garantias estabelecidas nos documentos internacionais mencionados. Essa nova declaração encontra-se à espera das necessárias subscrições para entrar em vigor.

\section{5 - A (IN)VALIDADE DAS UNIDADES DE CON- SERVAÇÃO SOBRE OS TERRITÓRIOS COMU- NAIS}

Maria Luiza Grabner já ponderou que "conhecer como se deu o processo de criação das Unidades de
Conservação é fundamental para a solução jurídica a ser alcançada" (2016, p. 84). Vimos, nos tópicos precedentes, que a imensa maioria das unidades de conservação recaídas sobre as comunidades quilombolas - e tradicionais como um todo - foi instituída, de maneira unilateral, sem concessões democráticas mínimas, no período ditatorial militar, entre os anos 1960-1980, neste Estado e no restante do país. Quase todos os acervos conservacionistas foram implementados por decretos, sem consultas prévias às comunidades.

No limite, e diante da carta de direitos humanos, a construção jurídica das unidades de conservação integral, tal como concebida, dentro dos limiares do liberalismo ocidental, constituiu-se na transposição formal e compulsória dos territórios ocupados pelos agrupamentos tradicionais para o Estado, criando-se, após a construção de tal artifício, uma miríade de restrições viscerais sobre os modos de subsistência cultural e material dessas comunidades.

Ainda que em conformidade com o regramento interno do país, a implantação das restrições estatais sobre os modos de reprodução étnico-territorial dos povos tradicionais é patentemente contrária a diversas disposições internacionais de direitos humanos que vedam aos Estados-partes limitarem a eficácia ou os efeitos de seus dispositivos. Essas obrigações de respeito aos documentos internacionais podem ser conferidas, por exemplo, na análise do artigo 5.1 e 5.2 do Pacto Internacional Sobre Direitos Econômicos, Sociais, Culturais e artigo 29, "a", da Convenção Americana Sobre Direitos Humanos. Ou seja, uma vez subscritos a convenção ou o tratado, ao Estado compete honrar seus preceptivos, já que tais documentos são revestidos pelo jus cogens, robustecido pelo artigo 53 da Convenção de Viena Sobre o Direito dos Tratados (1969), o que significa que, além de obrigatória, a norma cogente não pode ser alterada pela vontade de um Estado. "A derrogação de norma imperativa só pode ser feita por norma de igual quilate, ou seja, a norma aprovada pela comunidade internacional como um todo" (RAMOS, 2016, p.191).

Como prova das possibilidades de contato entre o universal e o particular, é curioso notar que a teoria do jus cogens foi concebida por Francisco de Vitoria, assentada em sua ideia de universalis respublicae 
justamente para tentar imprimir ares de legalidade ao processo de espoliação colonial europeu sobre as terras e os povos da América. (FERRAJOLI, 2020, $p, 11)$. E aqui estamos nós no caminho inverso, de tentar, através da força desse instituto hermenêutico, demonstrar que também aos espoliados pela ordem dominante se é possível antever normas impregnadas de efetividade. Assim, volvendo ao caminho antes trilhado, resta irrefutável que unidades de conservação, tal como urdidas pelo Estado a partir de uma racionalidade conservacionista asséptica e hegemônica, causam: (i) restrições e sofrimentos aos integrantes das comunidades remanescentes de quilombos e outros assentamentos tradicionais aos quais venha se sobrepor; (ii) a normatização estruturadora desses espaços de "preservação" ambiental serve, também, para formalizar e legalizar a criminalização e marginalização dos modos de reprodução cultural e material dessas comunidades, aprofundando o histórico processo de opressão e dissipação societária tradicional; (iii) indisfarçáveis aniquilamentos ao conteúdo dos direitos econômicos, sociais, culturais, étnico-territoriais analisados e (iv) transposição do território ancestral para o domínio do Estado.

Não há como refutar a observação de que as unidades conservacionistas, tal como urdidas pelo Estado, afrontam o dever de respeito à cosmovisão centrada no direito ao etnodesenvolvimento garantido pela vasta carta de direitos humanos detalhada nos capítulos anteriores, mas, em especial, produzem o aviltamento ao direito à consulta e anuência prévia, e devidamente informada, das comunidades atingidas.

A simples hipótese de reassentamento, antevista no artigo 42 da Lei do SNUC, por si só é flagrantemente inválida quando confrontada ao direito fundamental de não remoção sem consentimento, fixado no artigo 16 da Convenção OIT 169. O direito à reprodução das formas de subsistência tradicionais, detido por tais comunidades, como o direito à caça e pesca artesanal, os pequenos roçados em escala familiar, as atividades devocionais calcadas na tradição ancestral, tudo isso foi suprimido pela instituição das unidades de conservação informadas pelo mito moderno da natureza intocada. Toda a normativa interna que embasa tais unidades é, portanto, irremediavelmente inválida, nula, perante a carta de di- reitos humanos no que se sobrepõe aos territórios quilombolas.

O que resta, do ponto de vista das soluções jurídicas, é saber-se a forma de invalidação. Se houver propensão ao controle de constitucionalidade (compatibilidade interna) sobre tais afrontas, todas as unidades de conservação urdidas, por decreto, antes da atual constituição, terão as normativas que lhes instituíram como revogadas no tocante a esses territórios, já que é indisputável no meio jurídico que normas incompatíveis com a constituição, mas anteriores a ela, ressumam revogadas (BARROSO, 2008, p.22). Leis subsequentes à nova ordem constitucional, como, v.g., a Lei no 9.985/2000, no que permite a remoção forçada das comunidades tradicionais e a restrição sobre os territórios comunais, são inquestionavelmente inconstitucionais, isso, sob o ponto de vista interno. Esse controle de constitucionalidade pode materializar-se pelo regime do controle concentrado ou incidental em prol das minorias (BARROSO, 2008, p. 54).

\section{6 - CONSIDERAÇÕES FINAIS}

Frente aos objetivos propostos, que visa analisar o conflito entre Unidades de Conservação e comunidades Quilombola, no que diz respeito ao direito ao meio ambiente e direitos sociais dessas comunidades, conclui-se, pelo estudo realizado, que pelo prisma internacional, todo o arco normativo das unidades de conservação sobrepostas a territórios de comunidades tradicionais, como as quilombolas, é nulo diante da carta de direitos humanos, já que com ela incompatível. É bom salientar que perante o controle internacional de convencionalidade não existe diferença entre o teor de uma lei interna, uma sentença ou ato administrativo, pois, na órbita das cortes internacionais e outros meios de proteção aos direitos humanos, os atos dos Estados são tidos como fatos jurídicos em sentido amplo (RAMOS, 2016, p. 305), passíveis de invalidação em caso de incompatibilidade.

Calha também ponderar, face às conclusões predispostas, que os remanescentes de quilombos e outras comunidades tradicionais não estão libertos dos encargos de respeito aos limites normativos de tutela ambiental. É certo que, se houver comprova- 
do avanço sobre tais limites, as sanções correspondentes, e ponderadas, são válidas, assim como o são a qualquer estamento social. Aqui se sustenta que apenas as restrições étnico-territoriais violadoras da juridificação ampla dos direitos humanos, como tantas vezes modulada, é que são incompatíveis com um controle consistente de convencionalidade, até porque por tempos imemoriais tais agrupamentos, em meio a seus saberes tradicionais, conviveram em harmonia com a natureza, se afigurando como um dos principais fatores de proteção ao que restou dos ecossistemas originários.

A busca pelo reconhecimento dessa invalidade/nulidade das restrições aos territórios comunais a partir da sobreposição vertical das unidades de conservação pode se dar por distintas formas, como as ações promovidas pelas associações dos remanescentes de quilombos vindicando não só a declaração de nulidade da unidade de conservação no tocante ao respectivo território como, por consequência, postulando provimento de reconhecimento jurisdicional do território tradicionalmente ocupado, nos limites propostos pela comunidade face à histórica omissão do Estado em fazê-lo; ou pela via da ação civil pública, por meio de algum legitimado concorrente, atuando em substituição à comunidade quilombola afligida. Diante das conhecidas dificuldades enfrentadas no sistema de justiça interno em se acessar um controle de convencionalidade efetivo, também é possível transpor esses conflitos aos sistemas regional ou global de proteção dos direitos humanos, seja pela via da tutela jurisdicional da Comissão e Corte Interamericanas de Direitos Humanos ou do controle estrito senso (ou convencional), formulado pelos comitês temáticos ligados ao sistema ONU (RAMOS, 2016, p. 392).

De qualquer forma, a via pelo sistema interno de justiça, além de extremamente morosa e complexa, está muito distante de ser a mais efetiva, já que o Brasil é internacionalmente conhecido como um verdadeiro monumento à injustiça social (HOBSBAWN, 1999, p. 397), cujo sistema interno de proteção aos direitos humanos é notoriamente falho, já que o Judiciário prima, historicamente, por ignorar as interpretações emprestadas à carta internacional de direitos humanos pela Corte
Interamericana ${ }^{13}$, fator a contribuir com a enorme fragilização e descrédito dos mecanismos internos de proteção aos direitos humanos.

Tamanhas as encruzilhadas que o ideal seria a construção, pelo Estado e comunidades tradicionais, em especial as quilombolas, de mecanismos de técnicas de mediação e solução alternativas de conflitos (SAMPAIO, 2007). Por exemplo, câmaras conciliatórias, a serem instaladas nas cidades/regiões próximas de agrupamentos quilombolas, e integradas não só pelos representantes das associações e líderes comunitários mas, também, por servidores e gestores das unidades conservacionistas; representantes das prefeituras envolvidas na disputa territorial; concessionárias de serviços públicos de energia elétrica, saneamento, serviços de saúde e educação, enfim, visando abrir canais de diálogos na busca de formas alternativas de resolução dos diversos conflitos imbricados nessas colisões de interesses, até mesmo alcançando a facilitação dialógica para o acertamento das bases territoriais e desenvolvimento dos modos de reprodução dessas comunidades.

Todavia, a insistência, pela ótica dos gestores estatais, no aprofundamento das restrições aos modos de vida dessas comunidades, destoa da esfera jurídica, pois não há razões jurídicas, como visto, para fundamentá-las, e desemboca na perpetuação de uma tradição política concebida nos tempos da ordem moral das senzalas, profundamente arraigada nas instituições sociais, da qual é muito difícil, apenas pelos esforços institucionais internos, escapar, pois presa "à túnica rígida do passado inexaurível, pesado, sufocante" (FAORO, 2001, p. 834).

13 Exemplos emblemáticos das contradições de instituições brasileiras em relação a comandos internacionais de direitos humanos podem ser extraídos do caso Gomes Lund (Guerrilha do Araguaia) vs. decisão do STF chancelando os efeitos da lei de anistia aos militares e torturadores que operaram na repressão durante a ditadura civil-militar, provimento esse contrário à decisão da Corte Interamericana que determinou série de providências no sentido de afastar os efeitos da anistia, investigar, julgar e punir os responsáveis pelas violações (Ramos, 2016 b, p.392/403); ou a decisão, também do STF no RE 466.343, criando um tratamento dúplice aos tratados e convenções internacionais de direitos humanos: os documentos anteriores ao advento do §3으 do artigo 5응 da CF, introduzido pela EC 45/04, são recebidos, por esse engenho judicial, como normas "infraconstitucionais mas supralegais" e as produzidas após e por esse rito legislativo teriam status de normas constitucionais, fenômeno que motivou críticas como as do jurista Antonio A. Cançado Trindade, que atribuiu a essas "inovações" um "retrocesso e um imbróglio tão ao gosto de publicistas estatocêntricos, insensíveis à necessidade de proteção aos direitos humanos". Apud Ramos, op. cit, p. 316. 


\section{REFERÊNCIAS}

ABRAMOVICH, Victor e CHRISTIAN Courtis. Direitos Sociais são exigíveis. Porto Alegre: Ed. Dom Quixote, 2012.

ANDRADE, Anna Maria de Castro. Estudo Antropológico do Quilombo da Fazenda, Ubatuba-SP, contido no processo administrativo de titulação ITESP $\mathrm{n}$ 은 237/2007, SP datado de março de 2007.

ARRETCHE, Marta T.S. Emergência e desenvolvimento do Welfare Sate. BIB, Rio de Janeiro, 1995.

BARROSO, Luís Roberto. O controle da constitucionalidade no direito brasileiro. São Paulo. Saraiva. 2008.

BRASIL. Supremo Tribunal Federal. Notícia Do Julgamento Da ADIn 3239: <http://www.stf.jus.br/portal/ $\mathrm{cms} /$ vernoticiadetalhe.asp. ?idconteudo $=288144>$ Acesso em 4.1.2017.

BRASIL. Supremo Tribunal Federal. ADIn 3239: Pet inicial disponível em <http://redir.stf.jus.br/estfvisualizadorpub/jsp/consultarprocessoeletronico/ ConsultarProcessoEletronico.jsf?seqobjetoincidente $=2227157>$. 2004.

BRASIL. Justiça Federal. Mandado de segurança $\mathrm{n}$ o 0009700-10.2006.4.01.3400, em curso pela 5ạ Vara da Justiça Federal em Brasília-DF. 2016. Disponível em <http://processual.trf1.jus.br/consultaProcessual/processo.php?proc $=00097001020064013400 \&-$ secao=TRF1\&pg=1\&trf1 captcha id =5f95119a440c c48e43cc0a77f62e1eb5\&trf1_captcha=q64j\&enviar=Pesquisar $>$ Acessado em: 07.2.2017.

BRASIL. Funai.: <http://www.oas.org/es/council/ AG/regular/46RGA/documents.asp>. Acesso em 16.12.2016.

CANÇADO TRINDADE, Antonio Augusto. Direito Internacional e Direito Interno: sua interação na proteção dos direitos humanos. São Paulo: Centro de Estudos da PGE - Instrumentos Internacionais de Direitos Humanos, 1996.

CPISP - Comissão Pró-Índio de São Paulo <http://www. cpisp.org.br/comunidades/html/i_brasil_sp.html>. Acesso em 5.1.2017

CORTE, Interamericana de Direitos Humanos. Sentença caso Mayana, Awas Tigni vs Nicarágua. J. de 31.08.2001. <www.corteidh.or.cr>. 2001.
CORTE, Interamericana de Direitos Humanos. Sentença caso Yakye Axa vs. Paraguai. J. de 17.08.2005. <www.corteidh.or.cr>. 2005.

CORTE, Interamericana de Direitos Humanos. Sentença caso Pueblo Saramaka vs Suriname. J. de 28.11.2007. <www.corteidh.or.cr>. 2007.

CORTE, Interamericana de Direitos Humanos. Sentença caso Moiawana vs Suriname. J. de 15.6.2005. www. corteidh.or.cr. 2005 "b".

COUTINHO, Diogo R. Direito, desigualdade e desenvolvimento. São Paulo: Ed. Saraiva, 2013.

DIAS, Marina. O problema do menor é o maior. Jornal Le Monde Diplomatique Brasil. Ano 8, no 96, julho de 2015

DIEGUES, Antonio Carlos. O mito moderno da natureza intocada. São Paulo: HIUCITEC. 1996

FAORO, Raimundo. Os Donos do Poder, 3a Ed. São Paulo: Ed. Globo, p. 834, 2001.

FERNANDES, Florestan. O negro no mundo dos brancos, 2a Ed.São Paulo:Global editora, 2007

FERRAJOLI, Luigi. A Soberania no mundo moderno. São Paulo: Ed. Martins Fontes, 2002.

FREIRE, Gilberto.Casa-Grande \&Senzala 34a ed. Rio de Janeiro: Editora Record, 1998.

GALEANO, Eduardo. As veias abertas da América Latina 36ạ ed. São Paulo: Paz e Terra, 1994

GRABNER, Maria Luiza. Os Caiçaras e as Unidades de Conservação. In NETO, Paulo Stanich. (coord.) Direito das Comunidades Tradicionais Caiçaras. São Paulo: Editora Café com lei, 2016.

HAYAMA, Andrew Toshio. Por um Meio Ambiente com gente: comunidades tradicionais e unidades de conservação na perspectiva da dupla sustentabilidade. In: Carlos Frederico Marés de Souza Filho; Clarissa Bueno Wandscheer; Liana Amin Lima da Silva. (Org.). Biodiversidade, espaços protegidos e populações tradicionais. Curitiba: Letra da Lei, 2013.

HOBSBAWM, Eric J. Mundos do Trabalho, São Paulo, Ed. Paz e Terra, 1984.

Era dos Extremos, São Paulo: Cia das Letras, SP 1999 
Terra, 2001.

A Era das Revoluções 13a Ed. São Paulo: Paz e

HOLANDA, Sérgio Buarque de. Raízes do Brasil. São Paulo, Companhia das Letras, 1998.

ITESP. Sobre número de quilombos em SP, ITESP, Disponível <http://www.itesp.sp.gov.br/br/info/acoes/ assitencia_quilombos.aspx>. Acesso em 13.01.2017.

JESUS, Jhonny Martins de. et al. Governo federal entrega quilombolas aos leões. In: Direitos Humanos no Brasil - Relatório da Rede Social de Justiça e Direitos Humanos. São Paulo, 2008.

JORDÃO, Silvia. Os vazios geográficos na conservação de áreas naturais no Estado de São Paulo e o isolamento das Unidades de Conservação de Proteção Integral - Uma situação que precisa ser revertida. São Paulo: MP/SP Temas de Direito Ambiental, 2015.

KATZ, Claúdio. Neoliberalismo, neodesenvolvimentismo, socialismo. São Paulo, Ed. Expressão Popular, 2016.

MAGNANI, Nathércia Cristina Manzano. Os direitos humanos e fundamentais dos povos indígenas e os juízes: olhares presentes na jurisprudência da Corte Interamericana de Direitos Humanos e do Supremo Tribunal Federal. São Paulo: Dissertação de Mestrado apresentada na Pontifícia Universidade Católica de São Paulo. 2013.

MAPA, Violência no Brasil em 2016: Homicídios por arma de fogo no Brasil. Flacso, Brasil, 2016.

NUPAUB, Núcleo De Apoio À Pesquisa Sobre Populações Humanas E Áreas Úmidas Brasileiras. Povos/ Comunidades Tracionais e Áreas Protegidas no Brasil: Conflitos e Direitos. Série Documentos e Relatórios de Pesquisa. Pró-Reitoria de Pesquisa USP. São Paulo: 2011.

ONU. Cedaw, Comitê. Alyne da Silva Pimentel Vs. Brasil. Comunicação n. 17/2008, § 21, Documento da ONU: CEDAW/C/49/D/17/2008,2011.

PACHECO, Tania. Desigualdade, injustiça ambiental e racismo: uma luta que transcende a cor. In: <http:// racismoambiental.net.br/textos-e-artigos/tania-pacheco/desigualdade-injustica-ambiental-racismo/> Acesso em 28 de agosto de 2013

PELUZO, Cezar. Voto proferido na ADIn 3239 em
18.04.2012. Disponível em <http://www.sbdp.org. br/arquivos/material/1459_ADI3239>. Acesso em 20.03.2017.

PRADO JUNIOR, Caio. Evolução política do Brasil: colônia e império. 21a Ed. São Paulo. Editora Brasiliense, 2008.

PRIOSTE, Fernando e BARRETO, André. Território Quilombola. Distrito Federal: Terra de Direitos. DF. 2012, acessível em <http://terradedireitos.org.br/wp-content/.../Cartilha-formação-com-jovens-quilombola. pdf>. Acesso em 19.12.2016.

RAMOS, André de Carvalho. Teoria Geral dos direitos humanos na ordem internacional 6a ed. São Paulo: Saraiva, 2016.

Processo internacional de Direitos Humanos, 5a Ed. São Paulo: Saraiva, 2016.

ROTHENBURG, Walter Claudius. Direitos dos Descendentes de Escravos (Remanescentes das Comunidades de Quilombo), Revista Internacional de Direito e Cidadania, n. 2, p. 189-206, out/2008.

SAMPAIO, Lia Regina Castaldi \& NETO, Adolfo Braga. 0 que é mediação de conflitos 1 ạ ed. São Paulo: Brasiliense, 2007

SARMENTO, Daniel. A garantia do direito à posse dos remanescentes de quilombos antes da desapropriação. in: <http://ccr6.pgr.mpf.gov.br/institucional/grupos-de-trabalho/quilombos-1/documentos/Dr_Daniel_Sarmento.pdf>. Rio de Janeiro, 2006. Acesso Nov/2016.

SÃO PAULO. ITESP. Sobre o número de quilombos em SP, ITESP, Disponível <http://www.itesp.sp.gov.br/br/ info/acoes/assitencia_quilombos.aspx>. Acesso em 13.1.2017.

SÃO PAULO. Tribunal de Justiça do Estado de São Paulo. JECRIM, comarca de Ubatuba-SP, processo $\mathrm{n}$ - 0000655-74.2009.8.26.0642. Disponível <https://esaj.tjsp.jus.br/cpopg/show.do?processo. codigo $=$ HUY0900170000 \& processo . foro $=642 \&$ uui dCaptcha=sajcaptcha_f2 be 6ce004ba4cf59d811fb70185f2e5>. Acesso: 7.2.2017, “a".

SÃO PAULO. Tribunal de Justiça do Estado de São Paulo. JECRIM, comarca de Ubatuba-SP, processo $\mathrm{n}$ - 0007912-19.2010.8.26.0642. Disponível <https://esaj.tjsp.jus.br/cpopg/show.do?processo. 
codigo $=$ HUY0A063S0000 $\&$ processo. foro $=642 \&$ uui dCaptcha=sajcaptcha_f2be6ce004ba4cf59d811fb70185f2e5>. Acesso em 07.2.2017, "b".

SÃO PAULO. Tribunal de Justiça do Estado de São Paulo. JECRIM, comarca de Ubatuba-SP, processo $\mathrm{n}$ 0 000642742.2014.8.26.0642. Disponível <https://esaj.tjsp. jus.br/cpopg/show.do?processo.codigo $=\mathrm{HU0000HL}$ T0000\&processo.foro $=642 \&$ uuidCaptcha $=$ sajcaptcha f2be6ce004ba4cf59d811fb70185f2e5>. Acesso em 07.2.2017, "c".

SÃO PAULO. Tribunal de Justiça do Estado de São Paulo. 3a Vara cível da comarca de Ubatuba-SP. Processo no 0000727-85.2014.8.26.0642. Dispoinível em: <https://esaj.tjsp.jus.br/cpopg/show.do?processo. codigo $=$ HU0000CNI0000\&processo. foro $=642 \&$ uui dCaptcha=sajcaptcha_f2be6ce004ba4cf59d811fb70185f2e5>. Acesso em dez/2016.

SÃO PAULO. Tribunal de Justiça do Estado. 1a Vara Cível da comarca de Ubatuba-SP. Processo no 100379203.2016.8.26.0642. Ação Civil Pública. Disponível <https://esaj.tjsp.jus.br/cpopg/show.do?processo. codigo $=$ HU00014BM0000\&processo. foro $=642 \&$ uuidCaptcha=sajcaptcha_f2be6ce004ba4cf59d811fb70185f2e5>. Acesso em dez/2016.

SÃO PAULO. Tribunal de Justiça. Agravo de instrumento no 2213095-60.2015.8.26.0000. Disponível em: <https://esaj.tjsp.jus.br/cposg/ search. do ?conversationld=\&paginaConsulta=1\&localPesquisa.cdLocal=5\&cbPesquisa=NUMPROC\&tipoNuProcesso $=$ UNIFICADO\&numeroDigitoAnoUnificado $=2213095=60-2015$. \& foro NumeroUnificado$0000 \& d$ e Pesquisa NuUnificado= 221 3095-60.2015.8.26.0000\&dePesquisa=\&uuid Captcha=>. Acesso em 7.2.2017. E-SAJ, 2015.
SILVA, Dimas Salustiano. Direito insurgente do negro no Brasil: perspectivas e limites do direito oficial. In Lições de direito alternativo. São Paulo: Acadêmica. 1994.

SILVA. Paulo Thadeu Gomes. Conceito de comunidade tradicional. In NETO, Paulo Stanich. (coord.) "Direito das Comunidades Tradicionais Caiçaras", São Paulo: Editora Café com lei, 2016.

SILVA, Simone Rezende da. Negros na Mata Atlântica, Territórios Quilombolas e Conservação da Natureza. São Paulo: Tese apresentada ao Programa de Pós-Graduação em Geografia Física do Departamento de Geografia da Faculdade de Filosofia, Letras e Ciências Humanas da Universidade de São Paulo, para a obtenção do título de Doutora em Geografia. 2008

STÉDILE, João Pedro. Questão agrária no Brasil 11ạ ed. São Paulo: Atual Editora, 2011

STRECK, Lenio Luiz. Jurisdição Constitucional e Decisão Jurídica. 3a ed. São Paulo: RT, 2013.

VIEIRA, Marcelo Garcia. Os direitos fundamentais das comunidades tradicionais - crítica ao etnocentrismo ambiental brasileiro. Rio de Janeiro: Lumen Juris, 2014 